\title{
Four novel thymidine phosphorylase gene mutations in mitochondrial neurogastrointestinal encephalomyopathy syndrome (MNGIE) patients
}

\author{
Y Çetin Kocaefe ${ }^{1}$, Sevim Erdem ${ }^{2}$, Meral Özgüçç,1,3 and Ersin $\operatorname{Tan}^{2}$
}

${ }^{1}$ Department of Medical Biology, Faculty of Medicine, Hacettepe University Ankara, Turkey; ${ }^{2}$ Department of Neurology, Faculty of Medicine, Hacettepe University Ankara, Turkey; ${ }^{3}$ TÜBITAK DNA/Cell Bank, Hacettepe University Ankara, Turkey

Mitochondrial neurogastrointestinal encephalomyopathy syndrome (MNGIE) is a rare autosomal recessive neurologic disorder characterised by multiple mitochondrial DNA deletions. In this study, five Turkish MNGIE patients are investigated for mtDNA deletions and TP gene mutations. The probands presented all the clinical criteria of the typical MNGIE phenotype; the muscle biopsy specimens also confirmed the diagnosis with ragged red fibres and cytochrome $C$ oxidase (COX) negative fibres. The mitochondrial DNA analysis revealed no deletions in the probands' skeletal muscle samples. We have identified four novel mutations in the TP gene while one of the patients also harboured a nucleotide change, which was previously reported as a mutation.

European Journal of Human Genetics (2003) 11, 102 - 104. doi:10.1038/sj.ejhg.5200908

Keywords: Mitochondrial myopathy; MNGIE; mtDNA deletions; thymidine phosphorylase; gliostatin

\section{Introduction}

Mitochondrial diseases are a group of heterogeneous and complex disorders. The pathology may reside in the mitochondrial DNA (mtDNA) or the nuclear genome. The inheritance pattern is used to be considered as mostly sporadic or maternally inherited. However increasing evidence indicate the involvement of nuclear genes in the replication of mtDNA and biogenesis of mitochondria. Mitochondrial neurogastrointestinal encephalomyopathy syndrome (MNGIE), is a rare neurologic disorder and a multisystem disease characterised by thin body habitus, ptosis and/or ophtalmoparesis, gastrointestinal system dysmotility and sensorimotor peripheral neuropathy. Mutations in the Thymidine Phosphorylase (TP) gene within the chromosome segment 22q13.32-qter were identified as the cause of MNGIE phenotype and compound heterozygous and homozygous mutations diminish leuko-

\footnotetext{
*Correspondence: Prof Dr Meral Özgüç, Hacettepe University Faculty of Medicine, Department of Medical Biology, Hacettepe Childrens Hospital, 06100 Sihhiye, Ankara Turkey. Tel: 90312305 2541; Fax: +90 3123110777; E-mail: mozguc@hacettepe.edu.tr

Received 27 May 2002; revised 9 September 2002; accepted 24 September 2002
}

cyte TP activity to less than $5 \%$ of normal controls. ${ }^{1}$ In this study we investigated five Turkish MNGIE patients for mutations in the TP gene. We have identified four novel mutations.

\section{Patients and methods}

The MNGIE diagnosis was established upon the criteria described by Hirano et al: ${ }^{2}$ (1) Ptosis and/or ophthalmoparesis, (2) gastrointestinal dysmotility, (3) peripheral neuropathy, (4) ragged-red fibres (RRF) or increased succinatedehydrogenase (SDH) activity in muscle biopsy. In addition thin body habitus was specifically looked for and the diagnosis was supported by magnetic resonance imaging (MRI). The patients' history and clinical findings are summarised in Table 1.

mtDNA analysis

Muscle biopsy specimens from the patients were kept at $-80^{\circ} \mathrm{C}$ until DNA extraction was performed using standard procedures. ${ }^{3,4}$ Southern transfer of PvulI digested DNA to a nitrocellulose membrane (Amersham, Hybond $\mathrm{N}+$ ) was carried out using standard techniques. Presences of deletions were investigated both by ECL direct nucleic acid 
Table 1 Clinical features of the patients included in the study

\begin{tabular}{lccccccccccc}
\hline Patient & $\begin{array}{c}\text { Age of } \\
\text { onset }\end{array}$ & $\begin{array}{c}\text { Age of } \\
\text { diagnosis }\end{array}$ & Consanguinity & Sex & $\begin{array}{c}\text { Height } \\
(\mathrm{cm})\end{array}$ & $\begin{array}{c}\text { Weight } \\
(\mathrm{kg})\end{array}$ & $\begin{array}{c}\text { GIS } \\
\text { problems }\end{array}$ & $\begin{array}{c}\text { Ptosis/ocular } \\
\text { impairment }\end{array}$ & $\begin{array}{c}\text { Sensorimotor } \\
\text { Neuropathy }\end{array}$ & $\begin{array}{c}\text { RRF (+) } \\
\text { COX ( }(+) \text { fibers }\end{array}$ & $\begin{array}{c}\text { Hyperintense } \\
\text { MRI lesions }\end{array}$ \\
\hline 1 & Childhood & 25 & 2nd degree & $\mathrm{F}$ & 131 & 36 & $\mathrm{D}+\mathrm{P}$ & + & + & + & + \\
2 & 21 & 24 & 2nd degree & $\mathrm{M}$ & 162 & 45 & $\mathrm{D}+\mathrm{P}$ & + & + & + & + \\
3 & 14 & 19 & 2nd degree & $\mathrm{M}$ & 155 & 24 & $\mathrm{D}+\mathrm{P}$ & + & + & + & + \\
4 & 18 & 24 & - & $\mathrm{M}$ & 164 & 39 & $\mathrm{D}$ & + & + & + & + \\
5 & 34 & 46 & 2nd degree & $\mathrm{M}$ & 170 & 47 & $\mathrm{P}$ & + & + & + & + \\
\hline
\end{tabular}

GIS, gastrointestinal system; D, diarrhoea; $P$, pseudo-obstruction.

Table 2 The mutations and polymorphisms identified in five MNGIE patients

\begin{tabular}{|c|c|c|c|c|c|c|c|}
\hline Patient & $\begin{array}{l}\text { Mutation } \\
\text { (Genomic) }\end{array}$ & $\begin{array}{l}\text { Codon } \\
\text { change }\end{array}$ & $\begin{array}{c}\text { Mutation } \\
\text { (Protein level) }\end{array}$ & Mutation & $\begin{array}{c}\text { Exon } 9 \text { T5438A } \\
\text { polymorphism }\end{array}$ & $\begin{array}{c}\text { Exon } 8 \text { T5022C } \\
\text { polymorphism }\end{array}$ & $\begin{array}{c}m t D N A \\
\text { depletion \% }\end{array}$ \\
\hline 1 & G5629A homozygote & $\mathrm{GCG} \rightarrow \mathrm{ACG}$ & A465T & Exon 10 & $(-/-)$ & $(-/-)$ & 90 \\
\hline 4 & T5453A & ATC $\rightarrow$ ATG & Splice site I54M & Exon 9 & $(+/+)$ & $(-1-)$ & 82 \\
\hline 5 & $\begin{array}{c}\text { C1912G } \\
\text { T5162C homozygote }\end{array}$ & $\mathrm{GCT} \rightarrow \mathrm{GCC}$ & L371P & $\begin{array}{l}\text { Exon } 2 \\
\text { Exon } 8\end{array}$ & $(-1-)$ & $(+/+)$ & 68 \\
\hline
\end{tabular}

labelling (Amersham) and radioactive $\left(\alpha^{32} \mathrm{P}-\mathrm{CTP}\right)$ labelled mtDNA as the probe. ${ }^{5}$ Autoradiography was performed on Kodak X-Omat films. mtDNA depletion analysis was performed utilising semi-quantitative PCR technique employing a single copy gene in the genome as internal standard and the quantitation process has been done using NIHimage software (NIH).

\section{Thymidine phosphorylase gene sequencing}

The DNA isolation from peripheral blood was performed as described before. ${ }^{3}$ DNA samples were PCR amplified using sequence specific primers for the coding exons of the TP gene. ${ }^{1}$ Amplified products were sequenced on $\mathrm{ABI}$ prism 377 DNA sequencing system.

\section{Results}

mtDNA analysis

The mtDNA deletion analysis of the muscle biopsy and peripheral blood samples revealed no deletions in the probands. The mtDNA depletion analysis revealed that patients have mtDNA depletions of various amounts compared to normal subjects (Table 2).

\section{Thymidine phosphorylase gene sequencing}

Out of the five patients that we investigated, four were homozygous and one was compound heterozygous for the TP gene mutations and one of these mutations has been previously described. Four of these are novel mutations. The results and the mutations are summarised in Table 2.

\section{Discussion}

Three diseases associated with multiple mtDNA deletions have been shown to be transmitted autosomally; autosomal dominant progressive external ophthalmoplegia, autosomal recessive cardiomyopathy and ophthalmoplegia and the MNGIE syndrome.

Our laboratory findings revealed no deletions in the muscle mitochondrial DNA samples of the probands. Previous reports indicate that multiple deletions may not be present in all the affected patients. ${ }^{1}$ We have utilised the standard procedure for the detection of the mtDNA deletions; the Southern blot procedure of the PvuII digested total DNA hybridised with the near-full-length mtDNA probe. ${ }^{5}$ mtDNA deletions in MNGIE patients may be altered with the association of other modulating factors.

One of the mutations that we have identified (g5314a) was previously described in one Greek and two Italian families ${ }^{6}$ and our results also confirm that this splice site mutation is most likely to be of Mediterreanean origin. This mutation causes the exon 9 to be skipped in the splicing process.

Of the four novel mutations that we have described, the G5629A mutation residing in exon 10 results in A465T aminoacid change in the $\mathrm{C}$ terminal of the TP protein. The C1912G mutation identified in patient 4 in a homozygous state resides in the 'glycosyl transferase family helical bundle domain' of the protein and most likely disrupts the function. The conservation of the sequence between different species harbouring the aminoacid change has been documented in Table 3. The other mutation in the patient 4 is a splice donor site mutation (T5453A). The consequence of this mutation at the RNA level is still under investigation. The T5162C mutation has been observed in two patients (patient 2 and 5) in a homozygous state. It is possible that this mutation may be of Anatolian geographic origin. The patient 3 who bears the T5162C mutation is 
Table 3 The $\mathrm{N}$ terminal region of various species and the aminoacid change caused by C1912G mutation in the glycosyl transferase family, helical bundle domain. (NCBI Conserved Domain Database)

P19971

$\mathrm{AB} 060274$

$\mathrm{NC} 002755$

$\mathrm{NC} 003030$

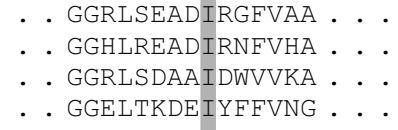

Human thymidine phosphorylase

Mus musculus thymidine phosphorylase

Mycobacterium tuberculosis thymidine phosphorylase Clostridium acetobutylicum thymidine phosphorylase also homozygous for the nucleic acid change C5648T that has been previously reported as a mutation in a Japanese family. ${ }^{6}$ However, this nucleotide change was originally described by Hagiwara et al. ${ }^{7}$ who depicted the chromosomal localisation and the organisation of the TP gene. They reported this as a variation between cDNA and genomic sequences of the TP gene. Our results also suggest that this nucleotide change although causes an aminoacid change at the very $\mathrm{C}$ terminal of the protein is most likely to be a variation rather than a mutation. This nucleotide change has also been referred as 'variant' at the gene bank protein database (accession: P19971).

We have also characterised two novel polymorphisms; one in Exon 8 (T5438) and one in Exon 9 (T5022) where both codon changes do not alter the amino acid sequence. The quantitative mtDNA depletion amounts of the patients documented are questionable upon the point of a functional impairment, as the mtDNA copy number values alter between $72-90 \%$ of the normals. We believe that it would be valuable to compare the relative mtDNA copy numbers of various tissues of an affected individual to a normal, as this may shed light on fundamental mechanisms of mtDNA copy number maintenance and distribution of the depleted mtDNA phenomenon.

It had been hypothesised that the alterations of the mitochondrial dTTP pools are the cause of disruption of mtDNA synthesis and multiple deletions in MNGIE patients as well as the manifestations of the MNGIE syndrome has been attributed to the toxic effects of high levels of thymidine in the MNGIE patients. ${ }^{8}$ As the exact mechanism underlying the quantitative mtDNA defects has not been revealed, this hypothesis is still far from satisfaction; specially when we consider the muscle as an effected endorgan where we observe all the manifestations of the mtDNA impairment but the TP gene expression is not detectable in this tissue. ${ }^{9}$ While there is a quantity of evidence suggesting multiple roles for TP protein; intracellularly $\mathrm{TP}$ is a biochemical catalyst, but extracellular duties are dependent upon the expressed tissue. TP is a focus of interest by oncologists as platelet derived endothelial cell growth factor (ECGF1) having a proposed role in tumour angiogenesis and metastasis as it stimulates angiogenesis in vivo. At the same time, $\mathrm{TP}$ in the central nervous system is known as Gliostatin inhibiting glial proliferation and implications on development and regeneration of the nervous system ${ }^{1.0}$
The overall picture and the manifestations of MNGIE syndrome taking into account the prominent central nervous system findings suggest that the pathophysiology of the disease is more complex than can be explained only by its metabolic basis. Our further studies are aimed at the identification of the functional role of TP protein in the developing central nervous system.

\section{Acknowledgements}

The authors would like to thank Ondokuz Mayls University Department of Neurology, National Railway Hospital and Ankara University Department of Gastroenterology for their patient referral and custom sequencing unit of GENETHON, Evry, France for help on sequencing.

\section{References}

1 Nishino I, Spinazolla A, Hirano M: Thymidine phosphorylase gene mutations in MNGIE, a human mitochondrial disorder. Science 1999; 283: 689-692.

2 Hirano M, Silvestri G, Blake DM et al: Mitochondrial neurogastrointestinal encephalomyopathy (MNGIE). Neurology 1994; 44: $721-727$.

3 Davis LG, Dibner MD, Batley JF: in Leder P. (ed.) Basic Methods in Molecular Biology. New York: Elsevier Science Publishing Co. Inc, 1986, (DNA extraction).

4 Wallace DC, Zheng XX, Lott MT et al: Familial mitochondrial encephalomyopathy (MERRF): genetic, pathophysiological, and biochemical characterization of a mitochondrial DNA disease. Cell 1988; 55: 601-610.

5 Dracapoli NC, Haines JL, Korf BR et al. (eds): Molecular analysis of oxidative phosphorylation diseases for detection of mitochondrial DNA mutations; in Current Protocols in Human Genetics. New York: John Wiley \& Sons, 1995 (Supp 7), Unit 9.9.

6 Nishino I, Spinazzola A, Papadimitriou A et al: Mitochondrial Neurogastrointestinal Encephalomyopathy: An Autosomal Recessive Disorder due to Thymidine Phosphorylase. Mutations. Ann Neurol 2000; 47: 792-800.

7 Hagiwara K, Stenman G, Honda H et al: Organization and Chromosomal Localisation of the Human Platelet Derived Endothelial Cell Growth Factor Gene. Mol Cell Biol 1991; 11: 2127-2132.

8 Spinazzola A, Marti R, Nishino I et al: Altered thymidine metabolism due to defects of thymidine phosphorylase. J Biol Chem 2002; 8; 277: 4128-4133.

9 Matsukawa K, Moriyama A, Kawai Y et al: Tissue distribution of human gliostatin/platelet-derived endothelial cell growth factor (PD-ECGF) and its drug-induced expression. Biochim Biophys Acta 1996; 8; 1314: 71-82.

10 Asai K, Nakanishi K, Isobe I et al: Neurotrophic action of gliostatin on cortical neurons. Identity of gliostatin and platelet-derived endothelial cell growth factor. J Biol Chem 1992; 5; 267: 20311 20316. 